\title{
CIÊNCIA DE ALMANAQUE: DIVULGAÇÃO CIENTÍFICA NAS PÁGINAS DE EU SEI TUDO
}

\author{
ALMANAC SCIENCE: SCIENTIFIC DIVULGATION ON THE \\ PAGES OF EU SEI TUDO
}

CIENCIA ALMANAQUE: DIFUSIÓN CIENTIFICA EN LAS PÁGINAS DE EU SEI TUDO

Dúnya Pinto Azevedo[i]

Clara Del'Amore Reggiani Martins[ii] Duane Henrique Alves de Carvalho e Silva[iii] Luiz Henrique Barbosa[iv] Ulissesdos Passos Rodrigues[v] Izabel Marques Cruz[vi]

\section{RESUMO}

Este artigo se propõe a analisar material de cunho científico que se mostrou relevante nas publicações de 1943 a 1952 do almanaque Eu sei tudo. Foram investigados a forma como o conhecimento relativo à ciência era tratado na época, as temáticas mais frequentes, a linguagem utilizada, os artifícios empregados, tudo isso levando em conta o público ao qual a publicação era direcionada. Para isso, fizemos um levantamento de todas as matérias relacionadas ao tema e selecionamos as que mais se aproximavam dos temas "tecnologia" e "ciência". Nossas análises permitiram concluir que, embora não possam ser definidos como "jornalismo científico", pois essa especialização não estava consolidada no campo da comunicação social, os textos possuem um caráter didático e utilizam artifícios para facilitar o entendimento do leitor, como infográficos e ilustrações. O caráter anedótico de algumas matérias e a não comprovação de algumas afirmações permitiu-nos que fizéssemos uma aproximação de seu

\section{ABSTRACT}

This article aims to analyze a scientific nature material that proved to be relevant in publications from 1943 to 1952 of the almanac Eu sei tudo. We investigated how knowledge related to science was treated at that time, the most frequent themes, the language used, the artifice used were investigated, all taking into account the audience to which the publication was directed. For this, we surveyed all matters related to the theme and selecte those that were closest to the themes "technology" and "science". Our analysis allowed us to conclude that, despite they cannot be defined as "scientific journalism", as this genre was not consolidated in social communication studies, there is a didactic character in the texts. They also use artifices to facilitate the reader's understanding, such as infographics and illustrations. The anecdotal nature of some articles and the lack of proof of certain statements allowed us to make an approximation of their informational content with literary fiction. We also

\section{RESUMEN}

Este artículo tiene como objetivo analizar material de naturaleza científica que mostró ser relevante en las publicaciones de 1943 a 1952 del almanaque Eu Sei Tudo. Fue investigada la forma en que se trató el conocimiento relacionado con la ciencia en ese momento, por medio de la investigación de los temas más frecuentes, el lenguaje utilizado, las artimañas utilizadas, teniendo en cuenta la audiencia a la que se dirigió la publicación. Para esto, realizamos; una encuesta de todos los contenidos relacionados con el tema y seleccionamos los que estaban más cerca de los temas "tecnología" y "ciencia". Nuestros análisis nos permitieron concluir que, aunque no puedan definirse como "periodismo científico", ya que este género no se había consolidado en el campo de la comunicación social, los textos tienen un carácter didáctico y utilizan artilugios para facilitar la comprensión del lector, como infografías e ilustraciones. La naturaleza anecdótica de algunos artículos y la falta de pruebas de ciertas declaraciones 
conteúdo informacional com a ficção literária. Verificou-se, ainda, a influência da cultura norte-americana em alguns dos textos analisados. Os hábitos e a cultura norte-americana serão usados para exemplificar alguns argumentos e os Estados Unidos serão vistos como um exemplo a ser copiado quando o assunto é desenvolvimento tecnológico e científico.

\section{Palavras-chave:}

Comunicação; Divulgação Científica; Eu Sei Tudo; Ficção Literária. verified the influence of American culture on some of the analyzed texts. We used some American habits and culture as examples. The United States can be a model when it comes to technological and scientific development.

\section{Keywords:}

Communication; Scientific Divulgation; Eu Sei Tudo Literary Fiction.

\section{INTRODUÇÃO}

A revista-almanaque Eu Sei Tudo começou a circular nacionalmente em 1917 e, em 1958, teve sua publicação encerrada. Editada no Rio de Janeiro pela Companhia Americana, a Eu Sei Tudo era uma publicação mensal ilustrada integrada à realidade urbana e foi, durante muito tempo, a forma pela qual os brasileiros se informavam. Diferentemente das revistas especializadas de hoje, que são voltadas para uma determinada área de conhecimento, tentava abarcar todo um universo simbólico, indo desde temas mais elitizados (cinema, artes plásticas, literatura, história, ciência, religião) até os mais frívolos (piadas, curiosidades, charadas), além de propagandas, informações sobre cursos, soluções práticas para resolver problemas domésticos. Daí o nome nem um pouco modesto do almanaque. Sua pretensão era a de dar conta de tudo, mostrar o mundo de forma caleidoscópica, nenhum assunto parece lhe escapar.

A partir da análise de como o conteúdo da revista era elaborado, podemos perceber sutilezas culturais relativas à época, motivo pelo qual tornou-se objeto de nossa pesquisa denominada "Eu Sei Tudo: Cultura plural em revista", cujo recorte temporal analisado é de 1943 a 1952. Essa pesquisa foi iniciada em 2016 e finalizada em 2019, tendo sido realizada com recursos da Universidade FUMEC, da FAPEMIG e da FUNADESP

Decidimos or esse recorte temporal devido à relevância do período para a compreensão das especificidades da conjuntura mundial - pós II Guerra e Guerra Fria - e sua relação com a cultura nacional. Sobretudo na década de 1950, nota-se com clareza a penetração da propaganda do american way of life e os rebatimentos da cultura norte-americana no estilo de vida brasileiro. A partir desse recorte, interessou-nos nos permitieron hacer una aproximación de su contenido informativo con la ficción literaria. También se verificó la influencia de la cultura estadounidense en algunos de los textos analizados. Los hábitos y la cultura estadounidenses serán utilizados para ejemplificar algunos argumentos y los Estados Unidos serán vistos como un ejemplo para ser copiado a respecto del desarrollo tecnológico y científico.

\section{Palabras clave:}

Comunicación; Difusión

Científica; Eu Sei Tudo; Ficción

Literaria.

pesquisar como os artigos que tinham como tema o conhecimento científico eram apresentados na revista. A nossa hipótese é de que ainda não havia o rigor característico dos textos jornalísticos que abordam a ciência, como imparcialidade, objetividade, explicitação de procedimentos de pesquisa. Muitas vezes o texto vai se aproximar da ficção literária, num movimento pendular entre informação e entretenimento, com o objetivo de atrair mais leitores.

Para a produção deste artigo, foram analisadas seis edições do almanaque em anos e meses diferentes (janeiro de 1943, março de 1945, julho de 1949, agosto de 1950, setembro de 1951 e outubro de 1952). As categorias mais recorrentes foram Psicologia, Astronomia, além de Medicina e Saúde.

\section{AS PUBLICAÇÕES PERIÓDICAS NO CONTEXTO DE MODERNIZAÇÃO DO BRASIL}

Orasil dos anos 1940/50 
estava em transformação. Após um longo período de restrições à importação, a indústria gráfica se renovou e cresceu vertiginosamente na década de 1950, graças, principalmente, aos investimentos do governo Juscelino Kubitschek. O aumento do número de publicações e as tiragens cada vez maiores com a introdução de novos métodos de composição e impressão impulsionaram o mercado e foram responsáveis pela formação de um público ávido pelo consumo de informações, seja por meio de textos, seja por meio de imagens.

Segundo Pereira e Brandão (1915), as revistas ilustradas brasileiras dessa época destacavam-se como meios de divulgação dos ideários das elites da Primeira República. Dessa forma, contribuíram, de forma efetiva, com o processo civilizador da sociedade carioca como lugar estratégico da difusão do ideário moderno. Outros exemplos dessas publicações são: O malho (1902 - 1954), Revista da Semana (1900 - 1940), Fon-Fon! (1907 1958), O Novo Correio das Modas (1852 - 1854) e A Estação (1879-1904).

Os moradores das cidades vivenciaram a experiência da leitura do almanaque num "novo mundo", urbano, republicano e, principalmente, industrial. 0 público ao qual a revista se destinava era bem amplo. Bollême (1969, p.32) discorre sobre as características do conteúdo e do público dos almanaques do século XVII e $X V I I I$. Elas também podem ser aplicadas ao almanaque Eu Sei Tudo:

llustrado com signos, figuras, imagens, o
Almanaque(...) reúne e oferece um saber para todos: astronômico, com os eclipses e a fase da lua; religioso e social, com as festas e especialmente as festas dos santos que dão lugar aos aniversários no seio das famílias: científico e técnico, com conselhos sobre os trabalhos agrícolas, a medicina, a higiene histórico com as cronologias, os grandes personagens, os acontecimentos

históricos ou anedóticos utilitário, com a indicação das feiras, das chegadas e partidas dos correios; literário, com anedotas, fábulas, contos; e finalmente astrológico. $\mathrm{Na}$ sua forma popular interessa sobretudo ao pastor e ao camponês (...) Ele obedece a uma grande lei que é sem dúvida aquela de toda leitura popular, é prazeroso e é útil.

A mídia da época se resumia ao rádio e aos veículos impressos, que ocupavam lugar de destaque como fonte de entretenimento e de informação. Com relação aos almanaques que circulavam à época, Carvalho (2011, p. 18) afirma: "Com um ar enciclopédico atenuado, essas pesadas publicações mensais ou quinzenais dividiam espaço com os jornais diários nas bancas."

Nesse clima de desenvolvimento industrial modernização e número crescente de público leitor, começam a se multiplicar também as publicações voltadas para a divulgação científica. As iniciativas de pesquisa e socialização da ciência no Brasil se deram de forma mais intensa a partir da segunda metade do século XIX. Como exemplos desse esforço no sentido da divulgação científica nas publicações podemos citar a Revista Brazileira - Jornal de Sciencias, Letras e Artes (1857), a Revista do Rio de Janeiro (1876) e a Revista do Observatório (1886) (MANSO, 2012).

Nessa época ainda não existia, por parte dos profissionais da comunicação, uma editoria específica (jornalismo científico) para tratar de assuntos da ciência. Isso só irá acontecer a partir da reforma universitária de 1961, época em que há uma proliferação de cursos de jornalismo e a formação de profissionais voltados para essa área. (VALERIO; PINHEIRO, 2008) E somente a partir dos anos 1970, há uma expansão do jornalismo científico, tendo como destaque a criação da Associação Brasileira de Jornalismo Científico (1977); o Prêmio José Reis de Divulgação Científica (1978); e a Revista Ciência Hoje (1982)

O jornalismo científico presente nas páginas de Eu sei tudo relaciona-se intimamente com as duas grandes Guerras Mundiais, que muito contribuíram para as temáticas de descobertas tecnológicas. É notório, nos artigos dessa área, o tratamento da ciência como uma área superior às demais, ainda que a ciência nos pareça embrionária no Brasil, devido à forma pela qual a informação relativa a essa temática é tratada, bem como suas

"Sabedoria, modernidade, evolução, conhecimento, avanço, futuro, esperança são algumas representações que a ciência assume nessas matérias." (CARVALHO, 2011, p. 22). O conhecimento é tratado quase como inacessivel, ou melhor, ao alcance de poucos "sábios", como diversas vezes são 
referidas as fontes das matérias; por isso deve ser divulgado de uma forma mais simples, didática, para o grande público.

\begin{abstract}
A ciência do almanaque de farmácia, saída dos bancos de escola, é muito mais história da ciência do que ciência propriamente dita. com ares de seriedade, a ciência (química, física biologia e matemática) é divulgada, popularizada, através de certas práticas ensinadas para serem repetidas, freqüentemente, como lazer, em serões, em família. Diríamos, até, uma ciência caseira, uma ciência lúdica. Lazer e utilidade parecem caracterizar o almanaque de farmácia enquanto leitura popular, que ensina, brincando, a adultos e crianças. (CASA NOVA,1999, p. 60)
\end{abstract}

Embora a citação acima se refira aos almanaques de farmácia, ela também se adequa ao almanaque Eu sei tudo. Podemos ainda interpretar a expressão História da Ciência não apenas como um conjunto de acontecimentos científicos ao longo do tempo, mas como narrativas e anedotas, formato utilizado muitas vezes pelas matérias que tratam de ciência. Isso faz com que o pretenso caráter científico dos textos se perca em alguns momentos, pois a narrativa é atravessada pelo ficcional, como veremos a seguir.

É importante aqui diferenciarmos os termos "comunicação científica" e "divulgação científica". Ambos, utilizados de forma intercambiável, se referem à difusão de informações sobre ciência, tecnologia e inovação. No entanto, há diferenças entre seus limites e sua abrangência. Segundo Bueno (2010), embora os conceitos apresentem características comuns, eles pressupõem aspectos bastante distintos no que concerne ao perfil de seus públicos, o nível de discurso empregado, à natureza dos canais ou ambientes utilizados para sua veiculação e a intenção explícita de cada processo em particular.

A divulgação científica compreende a "[...] utilização de recursos, técnicas, processos e produtos (veículos ou canais) para a veiculação de informações científicas, tecnológicas ou associadas a inovações ao público leigo" A comunicação científica, por sua vez, diz respeito à transferência de informações científicas, tecnológicas ou associadas a inovações e que se destinam aos especialistas em determinadas áreas do conhecimento. (BUENO, 2010, p.2)

Ao se referir ao perfil do público, Bueno explica que a percepção do público leigo de interesse da divulgação científica é difusa e muitas vezes equivocada, pois não reconhece o caráter coletivo ou burocrático da produção da ciência, e a individualiza. Segundo Bueno (2010), esse tipo de audiência confere à C\&T uma aura de genialidade, percepção reforçada pelo ensino formal da ciência que, em sua história, destaca individuos privilegiados (os cientistas geniais) e não o processo particular de produção. Também os meios de comunicação de massa favorecem essa percepção porque contemplam o avanço da ciência em momentos singulares e muitas vezes, de forma sensacionalista (BUENO, 2010).
Em consonância com as singularidades do público-alvo, também os níveis de discurso são distintos na comunicação científica e na divulgação científica. $\bigcirc$ uso de jargões técnicos e conceitos compartilhados entre o público da primeira definem um discurso especializado. Já para o público leigo, o discurso necessita passar por um processo de decodificação do discurso especializado, já que os termos técnicos são percebidos como ruído por esse público. Dessa forma, como explica Bueno (2010), a utilização de recursos (metáforas, ilustrações ou infográficos, etc.) podem facilitar a compreensão, mas podem também penalizar a precisão das informações. Isso acontece porque muitas vezes o jornalista ou comunicador não está capacitado para o processo de decodificação.

Os canais utilizados para a divulgação científica são, muitas vezes, os mesmos veículos de difusão de informações pela imprensa, por isso, confunde-se a divulgação científica com a prática do jornalismo científico. Mas, segundo Bueno (2009), essa prática extrapola o espaço midiático e se espalha por outros campos, como os livros didáticos, as palestras abertas sobre ciências, campanhas publicitárias etc, cumprindo importante papel no processo de alfabetização científica.

Bueno (2010) destaca a importância da divulgação científica, cuja intenção diverge da comunicação científica, na medida em que busca democratizar o acesso ao conhecimento científico, incluindo os cidadãos no debate sobre temas especializados que podem impactar sua vida. Por outro lado, a comunicação 
científica mobiliza o debate entre especialistas como parte do processo de legitimação do conhecimento científico.

\section{A REPRESENTAÇÃO DO CONHECIMENTO CIENTÍFICO NA EU SEI TUDO}

Após fazermos uma pesquisa em dez edições da revista (entre os anos de 1943 e 1952), selecionamos seis matérias para serem analisadas. Os critérios para essa seleção foram a necessidade de se apresentar como material consistente ou de maior fôlego (algumas delas são apenas notas, parágrafos sobre curiosidades científicas) e apresentar ilustrações ou infográficos como forma de facilitar a compreensão por parte do público leigo. Trata-se, então, de material de divulgação científica, embora não possamos defini-los como "jornalismo científico", uma vez que àquela época o jornalismo científico ainda não havia se consolidado como especialização no campo da comunicação social.

Dentre os assuntos mais recorrentes desse corpus estão astronomia - que especula sobre a vida fora da terra -, inovações tecnológicas, saúde, medicina, infância. As imagens são um importante aliado do conteúdo textual, uma vez que as matérias são bem didáticas. O que notamos, ao longo das análises, é que há pouca preocupação com as fontes e com as referências, e que, muitas vezes, o conhecimento científico perpassa diversas áreas do conhecimento. O didatismo e a superficialidade são características da maneira como a informação referente à ciência é tratada. A revista pretende ser uma fonte de informação sobretudo para as mulheres que ficavam em casa e precisavam se informar para ter o que conversar com seus maridos que chegam em casa após um dia de trabalho, informação obtida na matéria "Você teme o divórcio?", na edição de janeiro de 1952 do Almanaque Eu sei tudo.

Na edição de julho de 1949, uma matéria cujo título é "A Criança e O Brinquedo" apresenta um texto com aproximadamente duas páginas e meia, que é assinado por Margaret Jane Suydam. Em uma rápida pesquisa no Google, podemos encontrar no site da Amazon[1], a venda de alguns livros da autora, cuja temática de bebês é também tema da reportagem que leva sua assinatura na Revista Eu sei tudo. Não obtivemos nenhuma informação da profissão da autora.

O texto apresentado é dividido em cinco retrancas, marcadas por títulos secundários: "Como - brinquedo auxilia o desenvolvimento físico da criança", "Como o folguedo ajuda o desenvolvimento mental da criança", "Como o brinquedo ajuda o seu desenvolvimento emocional", "Como o brinquedo ajuda o desenvolvimento social" e "A importância do próprio brinquedo". Nesses tópicos, a autora discorre sobre as atitudes das crianças em diversas situações e quais os efeitos da interação da criança com o mundo que a rodeia.

Em nenhum momento é indicado algum tipo de pesquisa relacionado ao assunto, tudo é transcrito de forma taxativa, dado como verdade absoluta. Em uma das afirmações, por exemplo, a autora explica sobre o sofrimento da criança ao ser erguida no alto por um adulto:

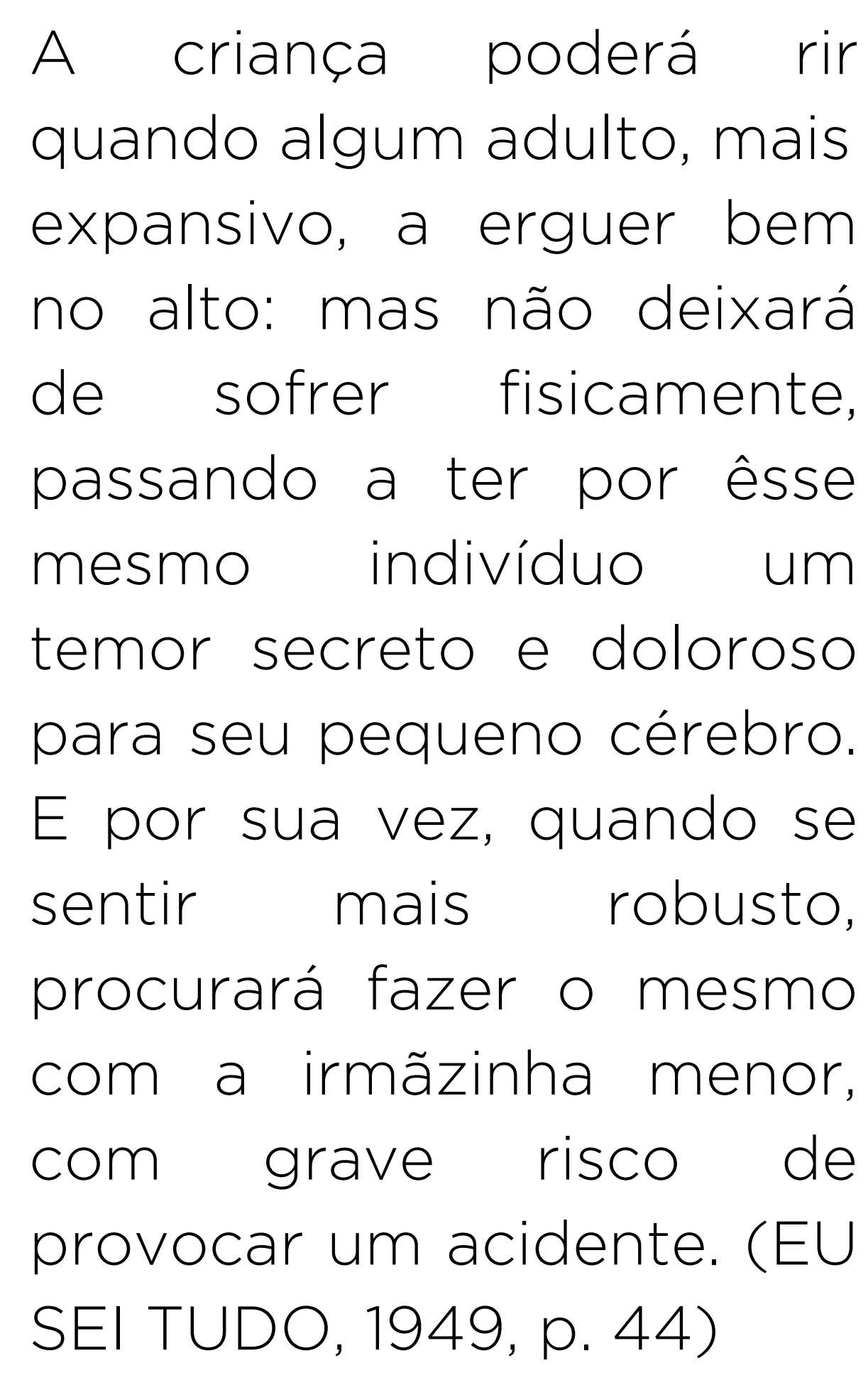

Acreditamos que na tentativa de ser o mais didática possível e evitar termos técnicos, a autora chega mesmo a infantilizar o leitor. Temos a impressão de que a linguagem acessível do texto ao público a que é dirigido dispensa comprovações e a legitimidade do que se afirma está simplesmente no fato de se tratar de uma publicação impressa, pois não temos informações sobre a autora que a legitimam em sua afirmação.

Matérias da área da Medicina também carecem do detalhamento de dados da pesquisa efetuada. "Membros fantasmas", publicada na edição de 1950, trata de casos de pessoas amputadas que, de acordo com a reportagem, ainda sentem os seus membros perdidos. São chamados de "membros fantasmas". A maior parte da reportagem é sobre as dores que esses "membros fantasmas" podem causar, mesmo sem existir.

A publicação não apresenta nenhuma fonte de pesquisa e chama a atenção em alguns pontos, como em um trecho que aparece uma frase de um amputado, mas não apresenta 
nenhuma fonte de pesquisa e chama a atenção em alguns pontos, como em um trecho que aparece uma frase de um amputado, mas não apresenta nome ou idade da pessoa. "Conta-nos um amputado recente", diz a reportagem. Em um outro ponto aparece $\mathrm{O}$ seguinte texto: "Um cirurgião informa que de 300 feridos amputados por ele só se recorda de 10 que não tenham sentido esse fenômeno". Não é citado o nome do cirurgião, nem do hospital onde trabalha. Na afirmação "As estatísticas do mundo inteiro admitem que o "membro fantasma" só se ausenta em 2 a 4 por 100 dos casos, apenas", nenhuma fonte da pesquisa é apresentada para legitimar essa informação. Três imagens ilustram o texto, sendo um desenho de um homem sem um dos braços (Figura 1), com uma projeção pontilhada de mãos, como se estivem surgindo do antebraço e outra imagem com a mesma projeção, mas em uma das pernas (Figura 2), que podemos definir como imagens que cumprem a função dos atuais infográficos[2], comuns em matérias jornalísticas, num esforço para deixar mais clara e mais didática a informação. A outra imagem (Figura 3) que ilustra a matéria é a de uma estátua sem cabeça, sem braços e sem pernas numa analogia precária à figura do amputado.

Figura 1: Ilustração da matéria "Membros Fantasmas"

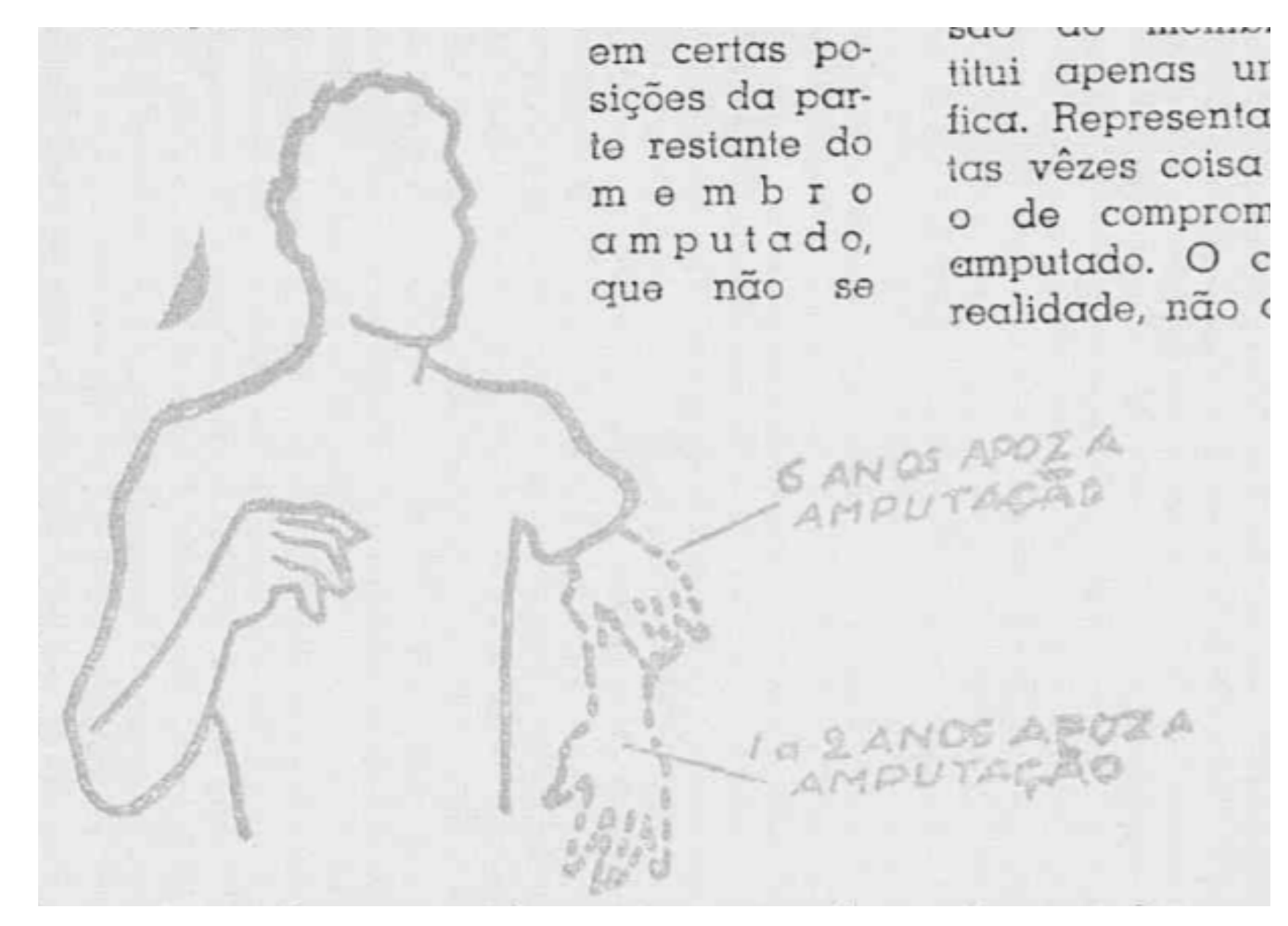

Fonte: EU SEI TUDO, 1950, p.16
Figura 2: Ilustração da matéria "Membros Fantasmas"

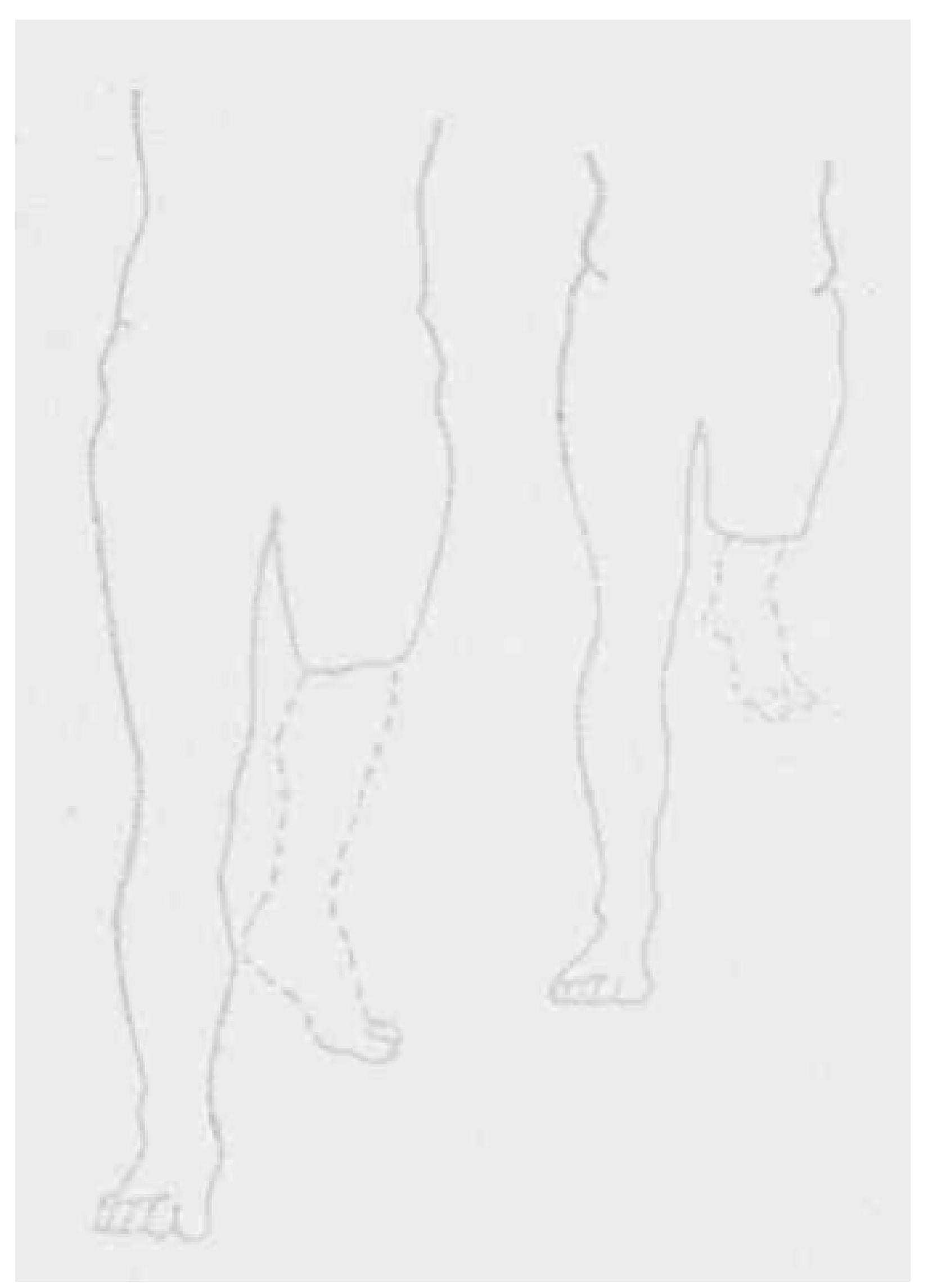

Fonte: EU SEI TUDO, 1950, p.17.

Figura 3: Ilustração da matéria "Membros Fantasmas"

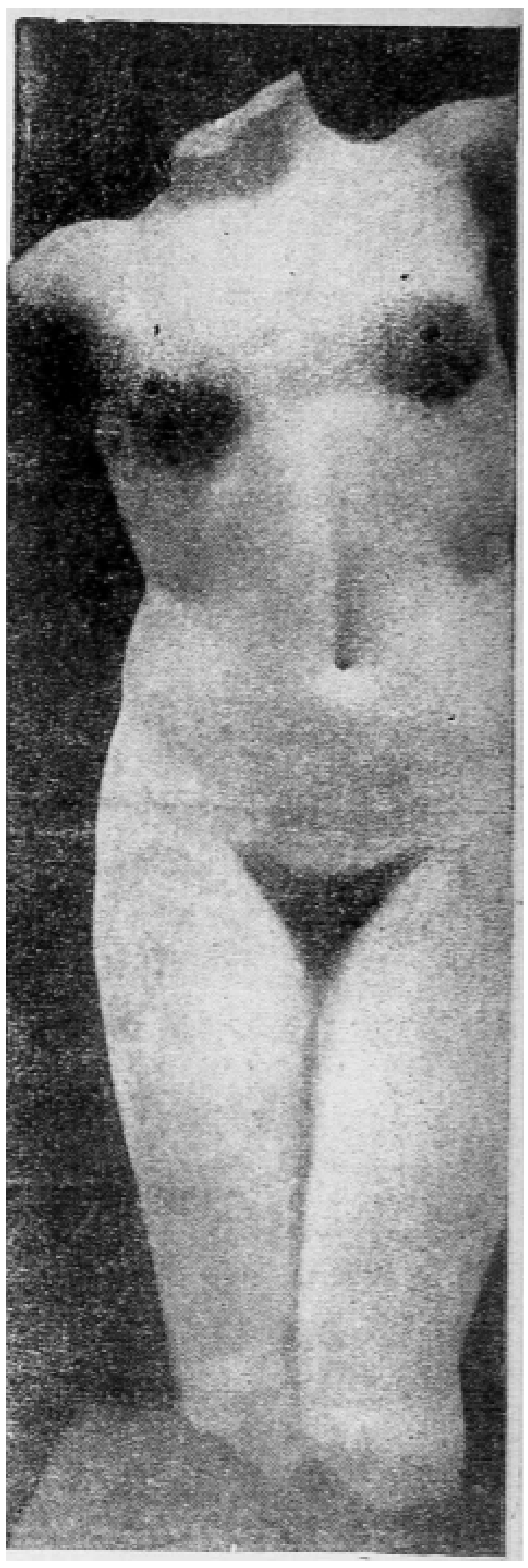

Fonte: EU SEI TUDO, 1950, p.17
Percebemos, ao analisar a reportagem a que nos referimos acima, que basta dizer que a pesquisa foi feita por um médico para que ela adquira confiabilidade. Não há necessidade de apresentar detalhadamente os processos metodológicos de um estudo. É o que podemos verificar na nota intitulada "Mulheres são mais sonhadoras", publicada na edição de janeiro de 1943. Nela é brevemente apresentado um estudo relativo aos sonhos, realizado por um médico austríaco que alega que as mulheres são mais sonhadoras do que os homens.

Não são apresentados os critérios da pesquisa, nem a metodologia utilizada para a obtenção dos resultados, apenas alguns números: "Segundo este sábio, de cada cem homens, vinte e sete apenas sonham com frequência, enquanto que de cem mulheres sonham frequentemente quarenta e cinco" (EU SEl TUDO, 1943, p. 46). O nome do médico não é citado, e ele é referido como "sábio". No final da reportagem, após a apresentação dos dados, lemos a seguinte frase: "...sempre confiando nas afirmações do sábio austríaco..." (p. 46) É interessante pontuar que a credibilidade da matéria está vinculada ao status da medicina, como se apenas dizer que se trata de um médico, estamos diante da verdade. Além disso, a matéria afirma que tal médico se estabeleceu em Chicago, o que dá ainda mais credibilidade para os fatos apresentados: além de europeu, fez carreira nos Estados Unidos, valores importantes à época.

Temas que se relacionam com o espaço despertavam muita curiosidade e especulações a 
respeito da vida e da possibilidade de visita à lua, o que aconteceu somente muitos anos após essas especulações. A primeira viagem à Lua ocorreu no ano de 1969. Na matéria "O foguete que irá à lua", publicada na edição de março de 1945, se inicia com o anúncio de um "foguete voador" que levará passageiros à lua, e posteriormente é seguida de exemplos da literatura de artefatos inventados possibilitando tal visita. Nenhuma outra informação acerca do foguete é mencionada, ressaltando a superficialidade da matéria. Especula-se também sobre a possivel presença de vida na lua, com elucubrações a respeito do tamanho dos pulmões e orelhas dos lunáticos:

Os habitantes da lua, se
existem, devem ter
pulmões excessivamente
desenvolvidos, para que
possam respirar a
atmosfera rarefeita. Suas
orelhas também devem ser
muito desenvolvidas e têm
de ser dotadas de ouvido
muito sensível, para poder
perceber as vibrações
sonoras transmitidas
através desse ar tão tênue
(EU SEl TUDO, 1945, p. 26)

Sempre com respaldo de professores da área, a matéria investiga a possibilidade de humanos visitarem a lua, mas isso rapidamente desconstruído, devido às dificuldades de tal feito, como a gravidade e a ausência de ar. A matéria associa a possibilidade dessa inusitada visita com o uso de submarinos e a necessidade de roupas especiais para suportar as condições de temperatura e pressão. No entanto, aqui, o autor do texto confessa que realidade e fantasia estão muito próximas: "Tudo isto - não será preciso dizer - é construir no mais completo reino da fantasia. Enfim estamos vendo tanta cousa, que... quem sabe?... talvez os nossos bisnetos cheguem algum dia a veranear na Lua." (p. 26). Drummond (2017) em sua comunicação intitulada "Lunários, almanaques e ficção" destaca o caráter ficcional dos almanaques: Lunário perpétuo e outros com os quais convivemos em leitura desde a infância, parece mesmo ter precedido a história à medida que uma espécie de tempo imemorial salta de suas páginas, e a vida passa a ser comandada pelos corpos celestes e seus segredos. Assim são os temas tratados, e assim e - caminho que ele vai abrindo para satisfazer a curiosidade do leitor e alimentar sua fantasia. Porque muito do almanaque é fantasia. O jogo da sorte é fantasia. A previsão do futuro se nutre da fantasia. A mesma fantasia que dá forma ao ficcional, que cria outro mundo contíguo à vida real, percorre o almanaque como resultado de sua recepção. Do ponto de vista formal, percebo que a linguagem do almanaque - a exemplo do Lunário perpétuo - se aproxima da prosa de ficção do século XVI e XVII, especialmente a prosa de função moralizadora, formadora do ethos e antecessora da pedagogia do eu préromântico cuja pretensão é difundir as altas verdades vitais, colhidas dos pensadores e sábios, de forma suave e quase coloquial.

A matéria da edição de outubro de 1952, intitulada "Marte É Realmente Habitado!" segue a mesma linha da matéria analisada anteriormente. Ela narra, por meio de supostos dados e relatos científicos de estudiosos creditados, a comprovação da existência de vida em Marte. Antes de se iniciar o texto, há uma ilustração (Figura 4), seguida da legenda "Em menos de dez anos estaremos fazendo viagens ao planêta Marte, em foguetes como êsse que vemos no clichê. A primeira viagem talvez necessite de duas semanas para ser completada." (EU SEI TUDO, 1952, p. 36).

Figura 4: Ilustração da matéria "Marte É Realmente Habitado

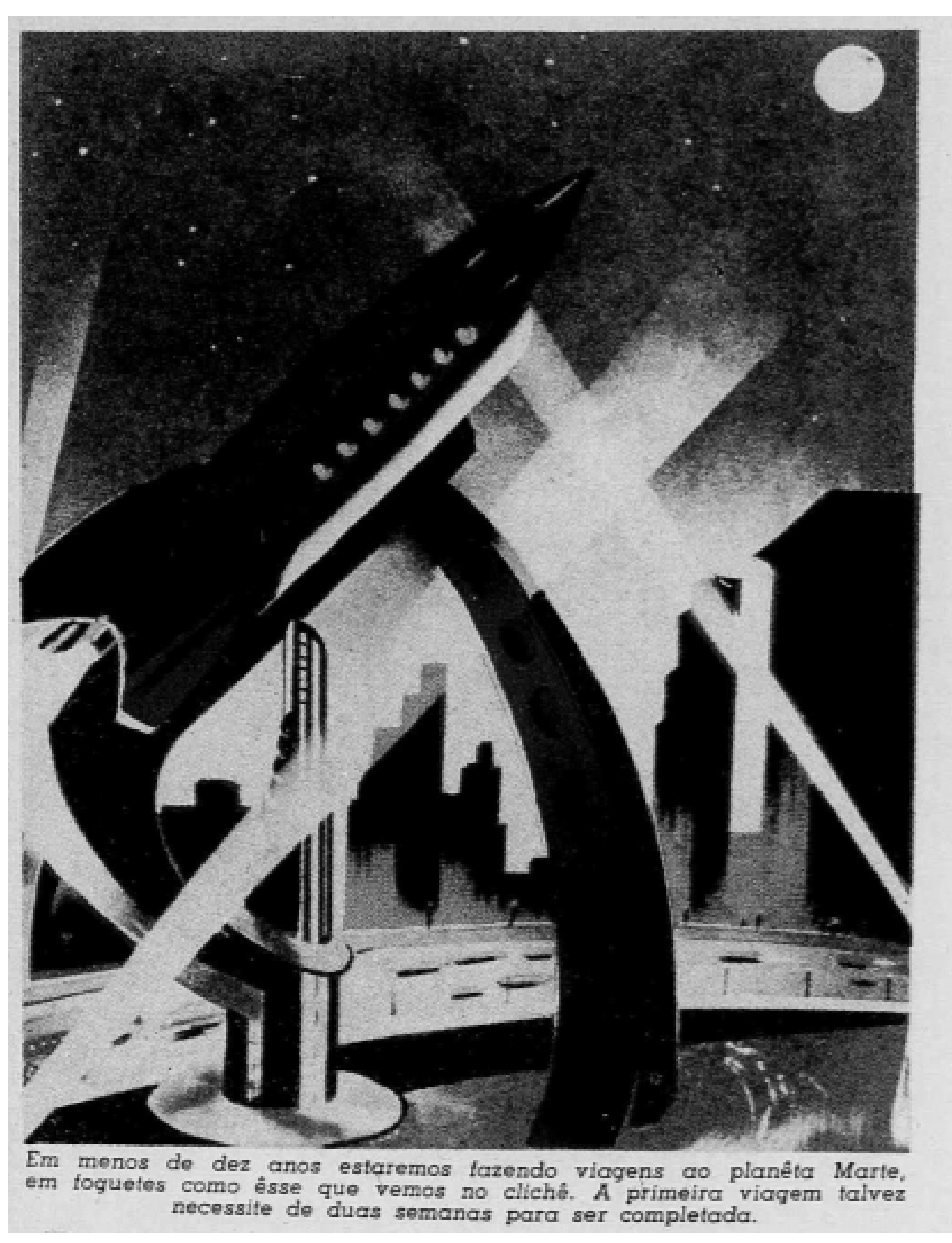

Fonte: EU SEI TUDO, 1952, p.36.

Afirma-se, com certeza, que em menos de uma década já haverá tecnologia capaz de viajar ao planeta vermelho. Não há qualquer comprovação ou argumentação para tal dado, mas ele é apresentado com informações específicas, como a contagem de "duas semanas", sem explicação de como esse cálculo foi feito. Além disso, a imagem usada para representar - foguete, que provavelmente seria como o usado em tais viagens, se assemelha aos modelos da ficção científica estrangeira da época, como as novelas de Buck Rogers, personagem criado por Phil Nowlan em 1928 para um conto 
literário e posteriormente adaptado para as histórias em quadrinho, o que levou à produção de algumas séries de $\mathrm{TV}$, com as quais conquistou sua fama.

Isso mostra a influência estrangeira, em especial, a estadunidense, no contexto brasileiro pós-guerra. Ao se referir a uma suposta descoberta de um cientista japonês de nome Tsuneo Saeki, diz-se ser "prova absoluta de que o planeta Marte não só suporta vida, mas também que essa vida é de ordem altamente inteligente" (p. 36). O uso do termo "prova absoluta" é uma tentativa de validar a informação, apesar de não haver qualquer validação científica comprovada no texto.

Sem trazer qualquer comprovação científica, fala-se que "o sábio", como se referem ao Dr. Seymour L. Hess, após ter uma "evidência", chegou à conclusão de que há água na superfície e na atmosfera de Marte. Isso foi "duplamente verificado pelas análises espectroscópicas" feitas pelo doutor, como é dito. Em seguida, completa-se: "Mais que isso, acaba de ser provado que a côr esverdeada da vegetação marciana é devida à presença da clorofila, a mesma substância que dá a côr verde a toda a nossa vegetação" (EU SEl TUDO, 1952, p. 38). Ao afirmar isso, o redator já parte do pressuposto de que existe vegetação em Marte e não apresenta qualquer comprovação relacionada ao fato citado.

Isso também aparece quando se diz "Em Marte, entretanto, existe vida tanto animal quanto vegetal, segundo os maiores astrônomos afirmam e atualmente se procura provar" (EU SEI TUDO, 1952, p. 37). A matéria confirma não só a existência de vegetação, como também de fauna, usando "os maiores astrônomos" como validação por uma figura de autoridade, mesmo que sem revelar quais seriam estes astrônomos. Mais uma vez se afirma, sem qualquer comprovação, com total certeza, ao se dizer "Está já agora plenamente provado que Marte possui essas duas coisas essenciais à vida que conhecemos: oxigênio e água" (EU SEl TUDO, 1952, p. 38). Curiosamente, em meio a tantas afirmações que tentaram de alguma forma se aproximar do estatuto científico desembocam na contradição: "Enfim, somente hipóteses". (EU SEI TUDO, 1952, p. 36).

A preocupação com a saúde do leitor, e como a ciência pode ajudar nisso, será também explorada pelo almanaque. $\mathrm{Na}$ edição de outubro de 1952, encontra-se a matéria cujo título é: "Você é 'Boa Vida'?" (Figura 5). Tratase de uma discussão acerca da descoberta de que, diferentemente do que se pensava, exercícios físicos não estão necessariamente ligados à boa saúde. O texto se abre com o trecho "Segundo um cálculo, aproximadamente 18.000.134 brasileiros vivem atormentados por um sentimento de culpa" (EU SEI TUDO, 1952, p. 24). A matéria se refere ao sentimento de culpa por não praticar esportes, já que, posteriormente, passa a explicar que tais exercícios não necessariamente levam a um corpo saudável. Não há, no texto, nenhuma referência sobre a fonte desse cálculo citado. O trecho é uma evidência clara da falta de comprovação aos dados apresentados na matéria, o que percebemos em outros textos da revista. Outra evidência desse fato seria o que é dito mais à frente, quando os redatores da matéria mencionam que o cientista Mark Twin "se antecipou" (EU SEI TUDO, 1952, p. 25) e fez sua descoberta antes de qualquer outro da Universidade de Colúmbia, onde trabalha, "sem qualquer auxílio da investigação científica" ( $p$ 25).

Figura 5: Ilustração da matéria "Você é 'Boa Vida?',.

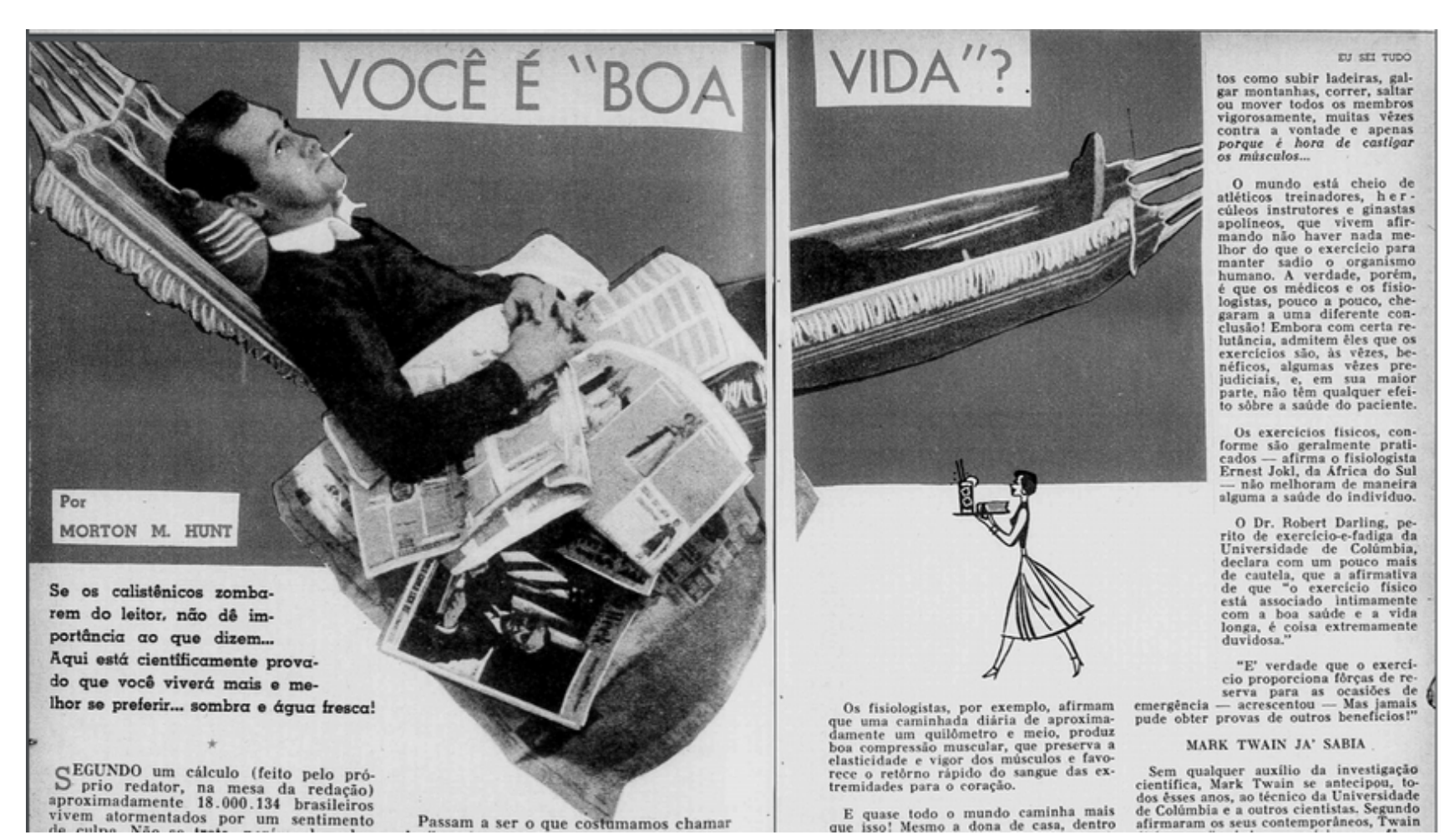

Fonte: EU SEI TUDO, 1952, p. 25

Além disso, outros dois fatores chamam atenção nessa matéria, que mostram a influência estadunidense no Brasil da época. Quando o redator menciona que a atividade física não é relacionada à boa saúde, ele explica que há, apesar de tudo, benefícios ao praticá-la, mas que estes não são como se pensavam. Para tal, ele diz "nem estamos considerando o benefício psicológico que o leitor pode obter, batendo com o bastão numa bolinha branca e saindo, depois, tranqüilamente, atrás dela" (EU SEI TUDO, 1952 p. 24), referindo-se claramente ao baseball, esporte sem expressividade no cenário brasileiro. Além disso, como um argumento, fala-se que "os Nazistas, como é sabido, eram verdadeiros maníacos calistênicos, obedientes a um programa rígido de 
treinamento físico e desenvolvimento muscular" (EU SEI TUDO, 1952, p. 26), assim, por associação, trazendo uma imagem negativa à prática esportiva, que, em seguida, é continuada com "já os norteamericanos democratas eram ligeiramente musculosos, verdadeiros "lutadores de cinema", como se dizia zombeteiramente. " (1952, p. 26). A linha de raciocínio culmina no trecho: "entretanto, esses 'heróis da tela' acabaram revelando ser melhores guerreiros que os seus energéticos adversários alemães" (1952, p. 26). O uso da palavra "guerreiros" para se referir aos soldados estadunidenses evidencia a posição martirizada do Estados Unidos no imaginário brasileiro da época, que parece se esquecer da participação das forças armadas nacionais na Segunda Guerra Mundial.

Curioso observar que a matéria termina com uma pequena nota, de teor humorístico, menosprezando todo o conhecimento científico ao dizer que o escritor Mark Twain já tinha chegado à conclusão da não necessidade da prática de exercícios físicos regulares para promoção da saúde bem antes dos cientistas. Diz a nota: "O único exercício ou esforço físico que praticara em toda a sua vida fora ajudar a carregar o caixão nos funerais de seus amigos que, estes sim praticavam regularmente a ginástica. " (EU SEI TUDO, 1952, p. 25)

O recurso humorístico também será bastante explorado na matéria intitulada "Vacina de álcool contra o alcoolismo". Valendo-se de um título que causa curiosidade no leitor, uma vez que a própria substância que causa dano à saúde é utilizada como cura, a matéria irá apresentar ao leitor o curioso tratamento:

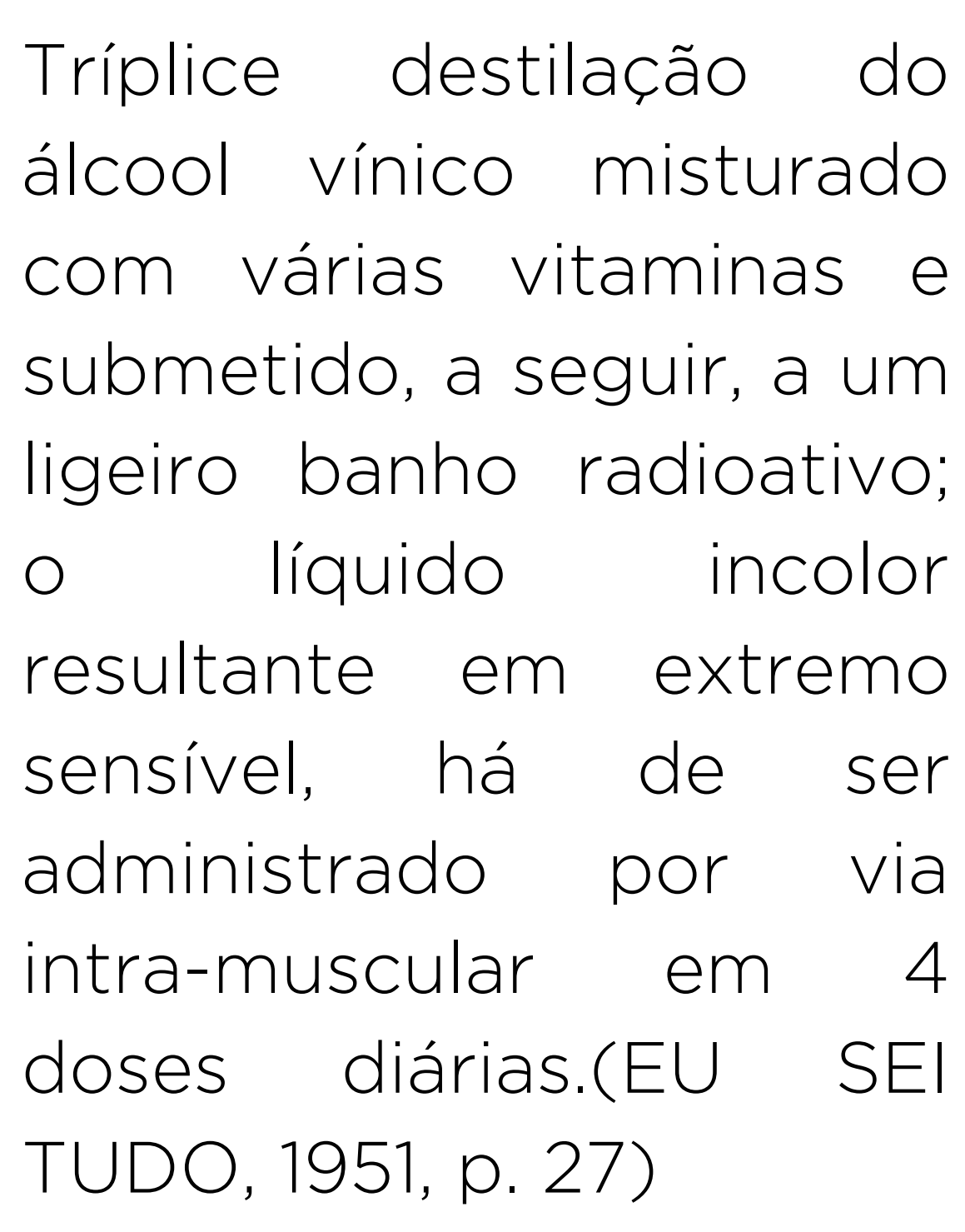

O articulista mostra que as experiências de desintoxicação mediante o álcool datam de anos anteriores. Os cientistas Larsen e Martensen pesquisavam uma cura para a solitária e resolveram ministrar a droga neles mesmos para observar aspectos como tolerância e outras reações. Convidados para uma reunião em que foram servidos cocktails, sentiram náuseas atrozes. Estava descoberta então uma vacina contra o alcoolismo por mero acaso. Nesse momento o jornalista abusa do humor:

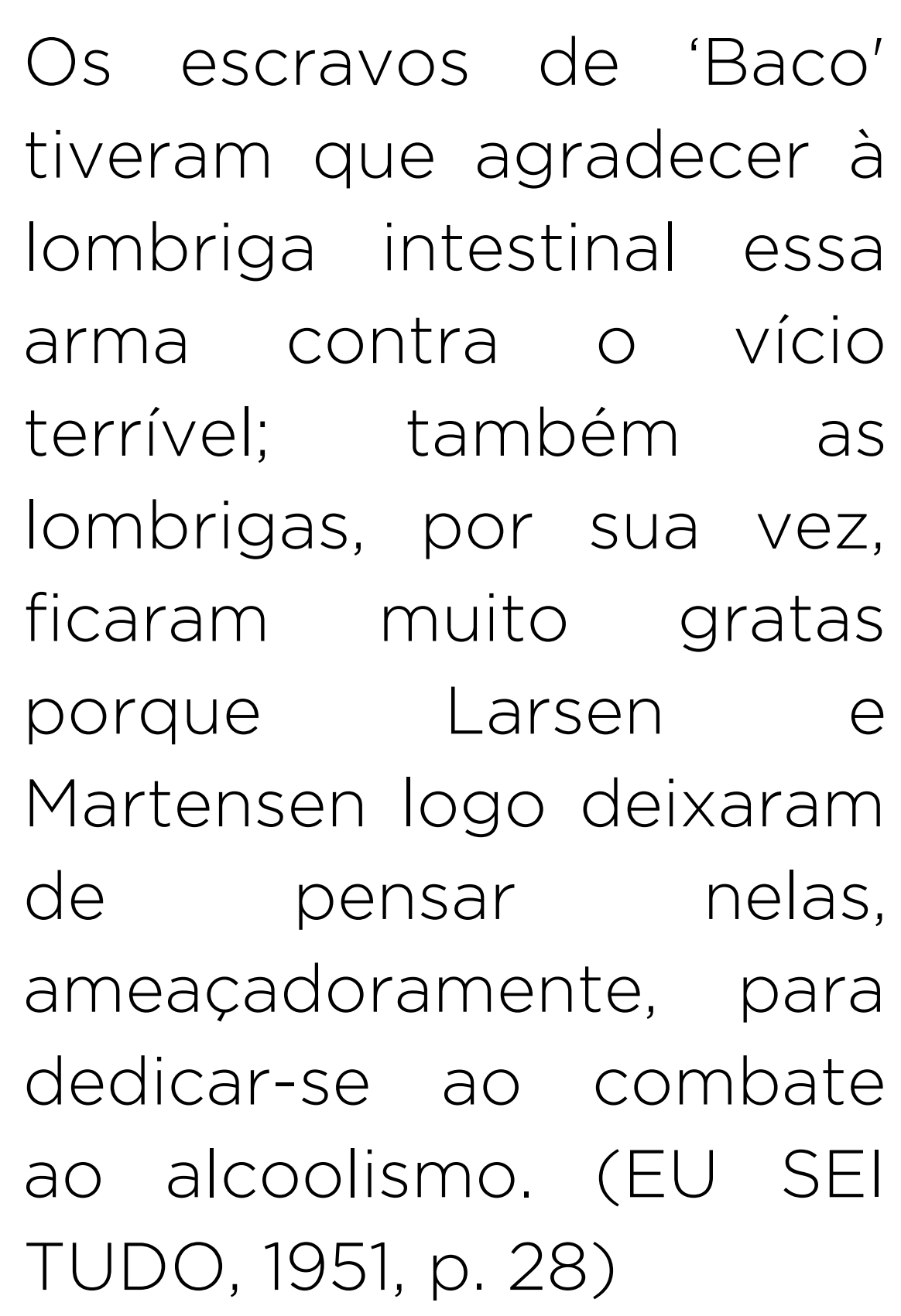

É perceptível que o jornalista não considera as bebidas alcóolicas responsáveis pelas condições em que os alcóolatras se encontram; mas sim as próprias pessoas que não sabem se controlar e se veem vítimas de uma mãos das donas de casa que não podem mais suportar um 'pater família' devoto dos copiosos tragos. Não faltará quem já esteja pensando em vacinar seu cônjuge." (1951, p. 29)

\section{CONSIDERAÇÕES FINAIS}

O Almanaque Eu Sei Tudo, já pelo seu próprio nome, emana o poder da sabedoria, liberando suas informações científicas das fontes e do detalhamento metodológico das pesquisas a que fazem referência. Assim, o leitor deve considerar como verdade 0 que está sendo anunciado pelo simples fato de ele ser publicado na revista ou de ser proferido por um sábio, forma como era tratado o cientista, o médico, o estudioso.

As análises das matérias que fizemos para a produção deste artigo nos ajudou a perceber a forma didática pela qual elas são construídas. Isso se deve provavelmente ao fato de o almanaque querer passar um conhecimento complexo e hermético, como o científico, de forma leve e prazerosa para o grande público ao qual se direciona. Assim, muitas vezes a abordagem da matéria é bem simplista e acompanhada de imagens que ilustram o conteúdo, também de forma didática.

A relação da ficção com o texto do almanaque Eu Sei Tudo é visível. Isso pode ser observado principalmente nas matérias relacionadas à exploração do universo. Como vimos aqui na matéria sobre a possibilidade da existência de vida em Marte, várias são as aproximações com a ficção científica, como a representação do foguete que levaria o homem ao planeta vermelho e a afirmação de 
existirem lá a flora e fauna, elementos indispensáveis para a vida humana.

Outro elemento que nos permite aproximar o almanaque da ficção literária é a linguagem utilizada pelas matérias. Muitas delas adotam o caráter de anedota e o jornalista terá sempre um caso para contar, como observamos na matéria sobre a descoberta casual de um tratamento para 0 alcoolismo. Além disso, é notório o caráter humorístico em algumas matérias, trazendo leveza à publicação e atraindo a atenção do leitor, como estratégia para entretê-lo.

Um outro aspecto notório do almanaque é a influência norteamericana sobre nosso país. Os hábitos e a cultura norteamericana são usados para exemplificar os argumentos apresentados, e os Estados Unidos são vistos como um exemplo a ser copiado quando o assunto é desenvolvimento tecnológico e científico. Uma visão que ainda hoje persiste em nossa sociedade.

NOTAS

[1] Disponivel em: https://amzn.to/2zhViJQ Acesso em: 23 maio 2020

[2] Infográfico é informação transformada numa combinação de explicações verbais e visuais interconectadas (WHITE, 2006).

\section{REFERÊNCIAS}

BOLLÊME, Genevive. Les Almanachs Populaires aux XVII et XVIII Siècles. Essai d'histoire Sociale. Paris: La Haye Mouton, 1969

BUENO, Wilson Costa. Comunicação Científica e Divulgação Científica: aproximações e rupturas conceituais. Informação e Informação. 15(1), p.1-12, 2010. Disponível em: https://bit.ly/2AQZoc1 Acesso em 27 abr 2020

BUENO, Wilson da Costa. Jornalismo científico: revisitando o conceito. In: VICTOR, Cilene; CALDAS, Graça; BORTOLIERO, Simone. (Org.) Jornalismo científico e desenvolvimento sustentável. São Paulo: All Print, 2009, p.157-78.

CARVALHO, Fabio Reynol de. Ciência de Almanaque: como as imagens de Eu Sei Tudo construíram uma guerra. 2011. Dissertação (Mestrado em Divulgação Científica e Cultural). Programa de Pós-Graduação em Divulgação Científica e Cultural, Universidade Estadual de Campinas, Campinas, 2011.

CASTRO MANSO, Bruno Lara Divulgação científica: o desafio de popularizá-la na própria ciência. Revista do EDICC, 1(1), p.47-57, 2012 Disponível em https://bit.ly/2A6LD8F Acesso em 27 abr 2020

DRUMMOND, M. Francelina Silami Ibrahim. Lunários, almanaques e ficção, Belo Horizonte: Universidade FUMEC. Não publicado

EU SEI TUDO. n. 308, jan. 1943. Rio de Janeiro: Companhia Americana. Disponível em http://bndigital.bn.br/acervodigital/eu-sei/164380. Acesso em 10 jun. 2018

EU SEI TUDO. n. 334, mar. 1945. Rio de Janeiro: Companhia Americana. Disponível em: http://bndigital.bn.br/acervodigital/eu-sei/164380. Acesso em 20 jun. 2018.
EU SEl TUDO. n. 386, jul. 1949. Rio de Janeiro: Companhia Americana. Disponível em http://bndigital.bn.br/acervodigital/eu -sei/164380. Acesso em 29 jun. 2018.

EU SEI TUDO. n. 399, ago.1950. Rio de Janeiro: Companhia Americana. Disponível em: http://bndigital.bn.br/acervodigital/eu-sei/164380. Acesso em 29 jun. 2018.

EU SEl TUDO. n. 412, set. 1951. Rio de Janeiro: Companhia Americana. Disponível em: http://bndigital.bn.br/acervodigital/eu-sei/164380. Acesso em 30 jun 2018.

EU SEI TUDO. n. 425, out. 1952. Rio de Janeiro Companhia Americana. Disponível

http://bndigital.bn.br/acervo-

digital/eu-sei/164380. Acesso em 15 ago. 2018

NOVA, Vera Casa. Lições de almanaque: um estudo semiótico. Belo Horizonte: Ed. UFMG, 1996

OLIVEIRA, Maria Coleta. Os Almanaques de São Paulo como fonte para pesquisa. In: MEYER, Marlyse (Org.). Do Almanak aos Almanaques. São Paulo: Ateliê Editorial, 2001.

RIBEIRO, Luiz Antônio, Guia dos Quadrinhos.

Disponivel em: https://bit.ly/2LQ8c4e Acesso em 20 ago 2018

VALERIO, Palmira Moriconi; PINHEIRO Lena Vania Ribeiro. Da comunicação científica à divulgação TransInformação, 20(2), p.159-169, 2008. Disponível em: https://bit.ly/2LUTylY Acesso em 23 maio 2020

WHITE, Jan V. Edição e Design: para designers, diretores de arte e editores, São Paulo: JSN Editora, 2006. 


\section{Artigo recebido em: 23 Jan 2020. I Artigo aprovado em: 02 Maio 2020.}

[i] Doutora em Comunicação Social pela Universidade Federal de Minas Gerais (UFMG), mestre em Design pela Escola Superior de Desenho Industrial (ESDI/UERJ), graduada em Comunicação Social (PUC/MG). Professora da Universidade FUMEC nos cursos de Mestrado em Estudos Culturais, Mestrado em Sistemas de Informação e Gestão do Conhecimento, e nos cursos de graduação em Jornalismo e Publicidade e Propaganda.

Orcid: https://orcid.org/0000-0002-1474-6124

E-mail: dunya.azevedo@fumec.br

[ii] Graduanda em Comunicação Social - Jornalismo pela Universidade FUMEC..

Orcid: https://orcid.org/0000-0002-4272-1813

E-mail: claradelamore@hotmail.com

[iii] Mestrando em Estudos Culturais Contemporâneos pela Universidade FUMEC. Bacharel em Comunicação Social (Publicidade e Propaganda) pela Universidade FUMEC.

Orcid: https://orcid.org/0000-0002-2249-9645

E-mail: duanealves@ymail.com

[iv] Doutor em Literaturas de Língua Portuguesa pela Pontifícia Universidade Católica de Minas Gerais (PUC MG), mestre em Estudos Literários pela Universidade Federal de Minas Gerais (UFMG), graduado em Letras (Língua Portuguesa) pela Universidade Federal de Minas Gerais (UFMG). Professor da Universidade FUMEC nos cursos de Mestrado em Estudos Culturais e nos cursos de graduação em Jornalismo e Publicidade e Propaganda.

Orcid: https://orcid.org/0000-0001-7447-4901

E-mail: luizhb@fumec.br

[V] Mestre em Estudos Culturais Contemporâneos pela Universidade FUMEC. Graduado em Eventos pelo Centro Universitário de Belo Horizonte. Orcid: https://orcid.org/0000-0002-0586-5201

E-mail: ulissesrn10@hotmail.com

[vi] Mestre em Estudos Culturais Contemporâneos pela Universidade FUMEC. Graduada em Design de Moda pela Universidade FUMEC.

Orcid: https://orcid.org/0000-0003-2119-1785

E-mail: izabelmarquesc@gmail.com 